\title{
NUMERICAL ESTIMATION OF THE FORMATION PROCESS OF ANTHROPOGENIC PRECIPITATION IN THE ATMOSPHERE
}

\author{
Dmitriy V. Gvozdyakov ${ }^{1,}{ }^{*}$, Vladimir E. Gubin ${ }^{1}$, Alexandr A. Gromov ${ }^{2}$, Anton O. Tanishev $^{1}$, \\ and Svetlana A. Shvab ${ }^{1}$ \\ ${ }^{1}$ Tomsk Polytechnic University, 634050, Tomsk, Russia \\ ${ }^{2}$ Nürnberg University of Technology Georg-Simon-Ohm
}

\begin{abstract}
The processes of condensation of sulfur trioxide $\mathrm{SO}_{3}$ and water vapor $\mathrm{H}_{2} \mathrm{O}$. Sulfuric anhydride is formed in flues of thermal power plants (TPP) by partial oxidation of $\mathrm{SO}_{2}$ (up to $5 \%$ of the total $\mathrm{SO}_{2}$ ) from the combustion of high-sulfur fuels, and belongs to a class of mild-hazard products. Sulfuric anhydride in the interaction with water vapor, which refers to greenhouse gases, under certain conditions, it forms sulfuric acid.
\end{abstract}

\section{Introduction}

One of the factors of the negative impact of thermal power plants (TPP) on the environment is the possible formation of acidic precipitation in areas immediately adjacent to the TPP $[1,9]$. Various pollutants released to the environment from the combustion of fuels [1].

In real practice the atmosphere always contains water vapor of natural origin [2]. In addition, a significant increase of the water vapor concentration in the air is possible in areas adjacent to the power plants by emissions of $\mathrm{H}_{2} \mathrm{O}$ due to the work of the heat engineering equipment of the station $[1,3]$. The analysis of processes of sulfuric acid drops formation in the air upon jointly proceeding processes of condensation of $\mathrm{SO}_{3}$ and $\mathrm{H}_{2} \mathrm{O}$ vapors on the condensation nuclei surface is of interest.

According to [1] it was assumed that the formation of sulfuric acid drops is the result of condensation of $\mathrm{SO}_{3}$ and water vapor at the surface of the "condensation nuclei" microscopic drops of water. The speed of the thermodynamic process significantly depends on the temperature [4]. Accordingly the reliability of the simulation results of condensation process is determined by the accuracy of the condensation surface temperature determination.

\section{Study technique}

The mechanism of the sulfuric acid formation [1] is based on cooperation, where sulfurous anhydride $\mathrm{SO}_{3}$ is absorbed by water vapor.

\footnotetext{
${ }^{*}$ Corresponding author: dim2003@tpu.ru
} 


$$
\mathrm{SO}_{3}+\mathrm{H}_{2} \mathrm{O} \rightarrow \mathrm{H}_{2} \mathrm{SO}_{4}+\mathrm{Q}
$$

The process of transfer of energy, momentum and mass in these circumstances is described by the system of non-stationary partial differential equations [5]. It is considered that the temperature and concentration on the left border of the solution domain (chimney of TPP) do not depend on time. Unsteady two-dimensional equations of mixed convection in the approximation of the Boussinesq approximation [6] are used to model the changes in the main sought for functions.

Calculation of the condensation rate was conducted using the formula [4]:

$$
W_{i}^{K}=\beta \cdot \frac{P_{A}-P_{0 i} \cdot \exp \left(-\frac{E_{i}}{R \cdot T}\right)}{\sqrt{\frac{2 \cdot \pi \cdot R \cdot T}{M}}},
$$

where $P_{A}$ - the atmospheric pressure, $\mathrm{Pa} ; P_{0 i}$ - the preexponent, $\mathrm{Pa} ; E_{i}-$ the activation energy of process of condensation, $\mathrm{J} / \mathrm{kg} ; R$ - universal gas constant, $\mathrm{J} /(\mathrm{mol} \cdot \mathrm{K}) ; M$-molar mass, $\mathrm{kg} / \mathrm{mol} ; \beta$ - the coefficient of condensation.

To solve the formulated boundary problem it was used the algorithm [7], developed for the decision of tasks of conjugate heat transfer in areas with a local energy source. Assessment of reliability of the obtained results was performed by verification of difference scheme conservative similar to [8].

The value of the coefficient of condensation of water vapor was varied in the range from 0.05 to 0.4 . Below are the results of numerical simulation of growth of sulfuric acid drops in the condensation process of sulfur dioxide and water vapor, calculated at a wind speed of $5 \mathrm{~m} / \mathrm{s}$ in summer.

Figure 1 shows the changes of the sulfuric acid drop sizes, depending on the time at various initial sizes of condensation nuclei.

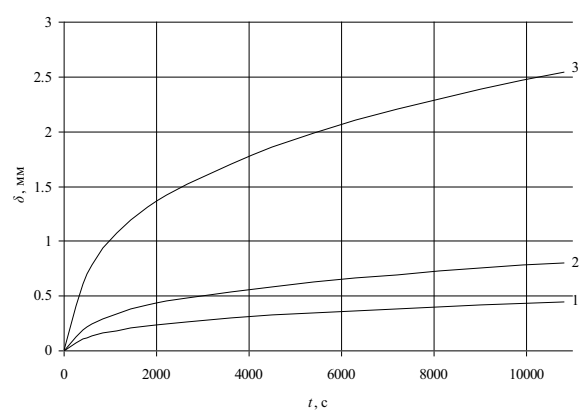

a

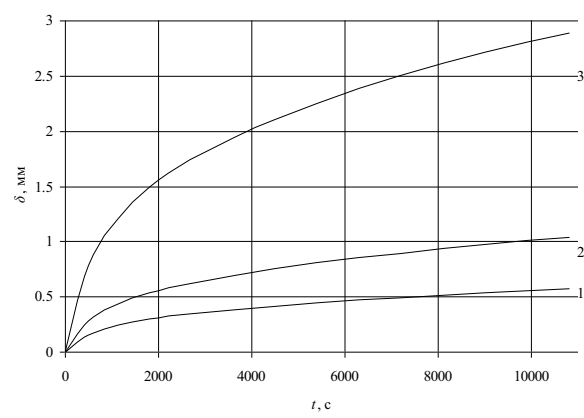

b 

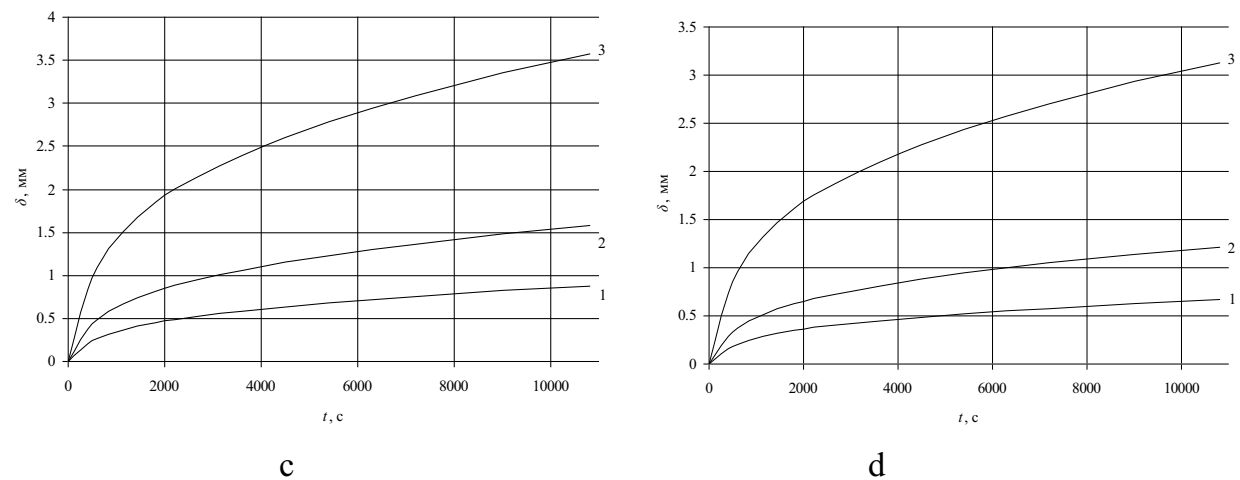

Fig. 1. Changes of the sulfuric acid drops size $\left(1-\delta_{0}=0.8 \cdot 10^{-6} \mathrm{~m} ; 2-\delta_{0}=1.0 \cdot 10^{-6} \mathrm{~m} ; 3-\delta_{0}=5.0 \cdot 10^{-6}\right.$ $\mathrm{m} ; \delta_{0}$ - the initial size of the condensation nuclei): a) $\beta=0.05$; b) $\beta=0.1$; c) $\beta=0.2$; d) $\beta=0.4$.

The results (Fig. 1) of numerical investigations show that when the coefficient of condensation $\beta=0.05$ it is possible to form the sedimentary acid precipitation already through $1800 \mathrm{~s}$ since the beginning of the process on the condensation nuclei surface $\delta_{0}=5.0 \cdot 10^{-6} \mathrm{~m}$. Further course of the simultaneous condensation process of sulfur dioxide and water vapor promotes the formation of sulfuric acid drops with sizes to $2.5 \cdot 10^{-3} \mathrm{~m}$ during the analyzed time interval.

It was established that formation of acid precipitation occurs on the condensation nuclei surface at $\delta_{0}=1.0 \cdot 10^{-6} \mathrm{~m}$ during 9000 and $7200 \mathrm{~s}$, respectively, in the range of changes of the condensation coefficient from 0.1 to 0.2 . For the considered period of time, the formation of sulfuric acid drops in the airspace adjacent to the power plants, with size from $1.0 \cdot 10^{-3} \mathrm{~m}$ to $1.2 \cdot 10^{-3} \mathrm{~m}$ is possible. Numerical evaluation of the particle border growth on the condensation nuclei surface at $\delta_{0}=5.0 \cdot 10^{-6} \mathrm{~m}$ illustrates the possibility of the sulfuric acid sedimentary drops formation during the $1800 \mathrm{~s}$ and $600 \mathrm{~s}$ since the beginning of the simultaneous introduction process of sulfur dioxide and water vapor at the surface of the "embryo".

\section{Conclusion}

The formation of sulfuric acid drops in the atmosphere of the Earth occurs more intensive on the condensation nuclei surface with initial size from $1.0 \cdot 10^{-6} \mathrm{~m}$ to $5.0 \cdot 10^{-6} \mathrm{~m}$ when the coefficient of condensation $\beta=0.05$ as the researches have shown.

The work has been supported by the Russian Federal focused program "Research and development on priority orientation of science and technology in Russia 2014-2020", unique identifier 'Applied Research and Experimental Developments' project RFMEFI58114X0001.

\section{References}

1. Ju. A. Izrajel', I. M. Nazarov, A. Ja. Pressman, Acid rains (Gidrometeoizdat, Leningrad, 1989) [in Russian]

2. D. V. Gvozdyakov, Web of Conference 82, 01026 (2015)

3. A. K. Vnykov, Protection of atmosphere from emissions of energy facilities (Energoatomizdat, Moskva, 1992) [in Russian] 
4. A. D. Labuncov, Physical fundamentals of Energy (MEI Publ., Moskva, 2000) [in Russian]

5. P. Rouch, Computational fluid dynamics (Moskva, World, 1980) [in Russian]

6. Paskonov, V.I. Polezhaev, L.A. Chudov, Numerical simulation of processes of heat and mass transfer (Nauka, Moskva, 1984) [in Russian]

7. G. V. Kuznetsov, J. Eng. Phys. 79, 56 (2006)

8. G. V. Kuznetsov, J. Eng. Thermophys. 18, 162 (2009)

9. K. V. Slyusarskiy, M. K. Bejsekov, J. V. Marysheva, Y. Ja Rakov, MATEC Web of Conferences, 37, 01053 